\title{
Review of School Belonging
}

Yuhui Qin, Xiang Wan

1Yuhui Qin, Department of Psychology, Wuhan University, Wuhan, Hubei, China

2Xiang Wan, Department of Psychology, Wuhan University, Wuhan, Hubei, China

Wuhan UniversityWuhan University

\begin{abstract}
School belonging can be concisely viewed as students' perception of being involved, recognized and supported. The prevailing form of assessments is self-reported questionnaires. Current researches find that school belonging correlates positively with academic performance and selfconception whilenegatively with problem behaviors, including school attrition, substance abuse and bullying. School belonging may be influenced by relationships with peers and teachers, involvement in school-based activities, identification with school values, academic performance and the grade. However, the effect of gender and ethnicity is still controversial and remains to be further scrutinized. Investigators propose three theories, that is, stage-environment fit theory, self-system theory and participation-identification theory to explain the mechanism of school belonging. Future orientations urges for longitudinal studies and experiments. Cross-cultural characteristics should be taken into consideration as well. The spectrum of participants should extend from a variety of students to staff in school.
\end{abstract}

Keywords : school belonging,school climate, academic performance, self-conception

\section{1 . INTRODUCTION}

As for school belonging, researchers mainly emphasize individuals' perception towards the facilities and relationships in school. At first, school belonging was roughly regarded as individuals' sense of being accepted, respected, included and supported in the school climate(Goodenow, 1993). Then the conception has been gradually enriched. Hagborg has taken a step further to assume that school belonging is the degree to which individuals feel respected and received among peers and teachers in school climate(Hagborg, 1994). Faircloth has claimed that school belonging can be expressed as positive association between individuals and school(Faircloth, 2009). And school belonging is viewed as individuals' identification with peers, faculties and the whole school climate(Cueto, Guerrero, Sugimaru, \& Zevallos, 2010). In brief, school belonging can be defined by three aspects:(1) social network in which individuals feel received, appreciated and obtain help from peers; (2) positive relationships between faculties and individuals where individuals are cared, recognized and encouraged by faculties; and (3) identification with school values as well as facilities and participation in a variety of school-based activities including extracurricular, cultural and sports activities in school climate(Faircloth \& Hamm, 2005; Lemberger, 2013).

\section{2 . Assessments of School Belonging}

Goodenow has designed the Psychological Sense of School Membership (PSSM) scale to measure the school belonging of students. It contains eighteen items such as "I feel like a real part of this school", which mainly indicates belonging to the school and relationships with peers and teachers in school.The scores range from 1(completely false) to 5(completely true). The internal consistency is good (.77.88)(Goodenow, 1993). Skaalvik extends this scale to assess faculties' school belonging. The alpha coefficient is .79(Skaalvik \& Skaalvik, 2011).

Hagborg has revisedthe PSSM scale and developed a multidimensional scale to assess school belonging. He has proposed three dimensions, belonging, rejection and acceptance. Belonging includes 11 items, which emphasize relationships with peers and teachers and participation in school activities. And Hagborg has proposed that this subscale can be used as an abbreviated scale to assess school belonging. Rejection contains 3 items, which indicate individuals' perception of acceptance among peers in school. Acceptance contains 2 items, which indicate whether the individuals identify with school climate. The scores range from 1(completely false) to 5(completely true). The internal consistency varies from .71 to .94(Hagborg, 1994, 1998).

Babakhani has updated the PSSM scale and developed a 15-item questionnaire to assess school belonging. It contains three dimensions, belonging( 6 items $)$, acceptance $(6$ items) and 
respect(3 items), which is the positive statement of Hagborg's rejection. It's a 5-point Likert scale, varying from 1(completely false) to 5(completely true). The alpha coefficients ranges from .71 to .82(Babakhani, 2014).

And You has revised PSSM scale and proposed a different 3-dimension scale to assess school belonging. Caring relationships contain 4 items, such as "Most teachers at this school are interested in me", which indicate the care and support given by faculties. Acceptance includes 5 items, like "Other students here like me the way I am", which stress on the acceptance of peers in school settings. Rejection comprises of 3 items, containing "Sometimes I don't feel as if I belong here", which indicate whether students identify with the school climate. The response ranges from 1(Completely false) to 5(completely true). The internal consistency varies from .78 to .95(You, Ritchey, Furlong, Shochet, \& Boman, 2010).

Wallace suggests that the construct of school belonging in high school students composes of four dimensions. One is generalized connection to teachers, which contains 5 items like "The teachers here respect me". This dimension indicates general perception towards faculties in school. Connection to a specific teacher involves 16 items, including "My teacher asks how she/he can help me", which highlight specific interaction with a particular teacher. Identification and participation in official school activities comprises of 6 items, such as "I feel proud to belong to school" "I am included in lots of activities in school", which indicate students' identification and involvement in school. Perception of fitting in with peers consists of 5 items, like "People at this school are friendly to me", which manifest whether individuals get along well with peers in school settings. It's a 5-point Likert-scale. The internal consistency ranges from .72 to .88 (Wallace, 2012).

\section{3 - Relationships Between School Belonging and Other Variables \\ 3.1 School Belonging and Academic Performance}

There are a variety of researches focusing on the influence of school belonging on academic performance. Some researchers concentrate on how school belonging contributes to academic motivation, an impulse to guide students' behavior in academic field(Ferreira, Cardoso, \& Abrantes, 2011). They argue that people intrinsically long for interacting with others and build up social bonds(Baumeister \& Leary, 1995). If they have mutual goals with others in school climate, the connection between students and others will be enhanced. In the relationally supportive settings, students will commit to the mutual goals and strive to fulfill the expectations of faculties and peers. In this sense, positive relationships with peers and teachers will be conducive to academic motivation in a long period(Walton, Cohen, Cwir, \& Spencer, 2012). Correlational studies have already demonstrated that positive relationships with peers and teachers in school climate correlate with academic motivation and expectation positively(Sancho, 2012).

Longitudinal studies reveal that academic motivation is promoted through sharing mutual interest with peers in academic performance(Walton et al., 2012). Meanwhile, weak school belonging has a negative impact on academic motivation(Ferreira et al., 2011). What's more, school belonging may serve the function of a scaffold for those who lag behind in academic field to hold on and continue education especially for marginalized people in disabilities, minority ethnic groups and remote regions since there may be fewer supportive resources available for them(Covarrubias \& Fryberg, 2014).

\subsection{School Belonging and Self- conception}

It's suggested that students may derive selfidentity from interaction with school norms, activities and significant others in school 
climate(Walton et al., 2012). And college students who have strong school belonging also possess higher self-worth(Pittman, 2007). And higher school belonging also predicts better evaluation towards school. Students with stronger school belonging tend to believe that school is intrinsically valuable to them(Neel, 2013).

Besides, one of the most important issues in this field is the relationship between school belonging and wellbeing. Previous researches have predicted that school belonging links to emotional outcomes(Goodenow, 1993). Some researchers propose that school belonging is positively associated with psychological wellbeing. Furthermore, it negatively predicts anxiety and depression and positively predicts emotional wellbeing and self-efficacy in school(Sancho, 2012). These consequences are extended to faculties and sexual minority youth in school(Skaalvik \& Skaalvik, 2011). As a crucial component of school belonging, positive relationships with teachers will predict the improvement of wellbeing of adolescents in school(Cemalcilar, 2010).

\subsection{School Belonging and Problem Behavior}

Most of the researches in this field engage in dropout, substance abuse and bullying. Some investigators pose that the perception of rejection and separateness is one of the crucial components in student attrition(O'Keeffe, 2013). And school belonging may be an ideal prevention to alleviate school dropout(Neel, 2013). Skaalvik applies this viewpoint to the resignation of faculties and proposes that school belonging is negatively associated with demission of faculties(Skaalvik \& Skaalvik, 2011).

And school belonging evolves into an important protective element against substance use, especially drugs. It's proposed that high school belonging will reduce the likelihood of abusing alcohol and marijuana(Rostosky, Owens, Zimmerman, \& Riggle, 2003). This theory works well in the girls of seventh and eighth grade and those who have few extracurricular activities available outside school settings(Drolet, Arcand, Ducharme, \& Leblanc, 2013).

Students who involve in bullying incline to consider the school settings as supportive of bullying and unfavorable. Bullying will get worse and the victims will feel more insecure(Goldweber, Waasdorp, \& Bradshaw, 2013). Immigrant students suffer more bullying than native students(Flores \& Clares-López, 2014). It's assumed that when students have higher school belonging, they tend to behave themselves and conform to the norms in school climate. The identification with school will make a difference in bullying issues(Turner, Reynolds, Lee, Subasic, \& Bromhead, 2014). To cease school violence and peer victimization, it's important to resort to school belonging.

\section{Influential Factors of School Belonging} 4.1 School Climate

It's proposed that norms, shared experiences and feedbacks have an impact on school belonging(Walton et al., 2012). And it's assumed that teacher support, peer support, participation in school activities and identification with norms in school are among the most significant factors of school belonging. Positive relationships with peers and teachers will predict higher school belonging while vexation and stigmatization provoked by peers and teachers will bring down school belonging(Maurizi, Ceballo, Epstein - Ngo, \& Cortina, 2013). And Cemalcilar emphasizes not only the effect of relationships with peers and teachers but also that of the facilities and climate of school on school belonging. It's suggested that the degree to which students are satisfied with these factors will noticeably influence school belonging(Cemalcilar, 2010).

And some investigators take a step further in teacher support to highlight the effect of empathy, welcome, care and counseling provided by teacher on school belonging (McMahon, 2008). Experienced teachers will promote the school belonging of adolescents 
with

Autism

Spectrum

Disorders(ASD)(Osborne \& Reed, 2011). As for teachers, identification with school value and positive relationships with colleagues and supervisors predict school belonging(Skaalvik \& Skaalvik, 2011).

\subsection{Demographic Variables}

Among demographic variables, ethnicity, gender and grades are taken into consideration. It's reported that minority ethnic groups have weaker school belonging. If they suffer stigmatization and frustration in school, they will be less likely to identify with school and develop school belonging while the major ethnic groups are less sensitive to the risky factors and more likely to maintain their school belonging(Covarrubias \& Fryberg, 2014). Coleman extends the conclusion to teachers and finds that those who suffer the stress of racial activism will be less likely to identify with school and develop school belonging(Coleman, 2013). The cause of this phenomenon is assumed to be entrenched in negative stereotypes of minority ethnic groups.However, some researchers argue that difference in ethnicity is not a significant predictor(Neel, 2013).

Besides, there are noticeable gender difference in school belonging. Girls are more inclined to commit to school and show higher school belonging than boys. This difference is reported to maintain in different ages and grade. Girl's school belonging tends to decline while boy's school belonging is more constant. Perhaps girls are more sensitive to the declining studentteacher relationship in transit from middle school to high school. And there may be fewer school activities and other resources available for girls, which results in the decline of school belonging of girls(Neel, 2013). Narges finds that boys have noticeably higher school belonging than girls in high school(Babakhani, 2014). Some investigators suggest that gender does not play a role in school belonging(Cueto et al., 2010).
As for grades, students in transit from middle school to high school have declining school belonging under different ethnic backgrounds(Neel, 2013).

\section{Theory of School Belonging}

\subsection{Stage-environment Fit Theory of School Belonging}

It's suggested that the disparity between students and the school settings contributes to the maladaptation of students. When the students enter adolescence, it's natural for them to long for more liberty and autonomy. However, most school may be authoritative and supply them few opportunities to act as their will in learning and establishing relationships. Those who report to be unsatisfied with the school climate show weaker school belonging. Hence, it's assumed that if the demand of students is not satisfied in the school climate, students show lower school belonging. On the contrary, if the school settings meet the developmental need of students, students tend to report stronger school belonging(Eccles et al., 1993; Wallace, 2012)

And Gagne comes up with an immigration stage-environment fit theory. It's claimed that generation status is of great importance in enhancing immigrant students' school belonging and identifying supportive resources in school for students. This theory views generation status as a mediator between peer support and school belonging(Gagné, Shapka, \& Law, 2014).

\subsection{Self-determination Theory of School Belonging}

Self-determination theory emphasizes the influence of relatedness on a variety of motivations and behavior. School belonging arises from school climate, including relationships with peers and teachers as well as participation in school-based activities. And school belonging plays a role in affecting the motivation and behavior of students. Overall, classic self-system theory stresses on the mediating role of school belonging. It's assumed that supportive school climate contributes to school belonging, which can 
predict students' motivation, interaction and other behaviors in school(Wallace, 2012).

However, some researchers think this theory underestimates the vigor of school contexts and reduces the school settings to a source of information and impulses. They suggest that the contexts can provoke academic motivation directly. Since people have intrinsic desires to belong to others, resist the disintegration of relationships and maintain the social bond, it's natural for students who want to identify with schoolto promote the shared motivation and behavior, which is represented by academic motivation, competence as well as participation in school activities(Baumeister \& Leary, 1995; Gagné et al., 2014).

\subsection{Participation-identification Theory of School Belonging}

Participation-identification deals with dropout. The success of participation in school activities is associated with identification with school settings. School belonging is one of the most important components in identification. And there are four essential patterns of participation(1) responses to norms, teachers' instructions and assignments in classroom; (2)academic motivation and pursuit for extending academic work; (3) participation in extracurricular activities in school climate; (4) taking part in the development of school, among which participation in classroom is the most crucial pattern and the quality of instructions will noticeably influence the success of participation in school activities and identification with school settings(Wallace, 2012; Wehlage, 1989). This theory is further developed by later investigators.

Faircloth proposes identity-instruction integration theory. It's proved that responses in classroom are contingent on the association between identification with school and learning process. If the classroom can provide the students with positive feedbacks, students will develop school belonging and identify with school. On the contrary, dissonance between learning environment and students' characteristics will result in negative affections, which may impede students from developing school belonging. Teachers' instructions will enhance students' academic motivation, school engagement and school belonging, which will alleviate school attrition(Faircloth \& Hamm, 2005; Wallace, 2012).

\subsection{Future Orientations of School Belonging}

There are a variety of issues that researchers should call attention to. Though the researchers have already extended the definition of school belonging from "included, respected, included and supported" to relationships with peers and teachers, identification with the school values as well as facilities and participation in schoolbased activities. However, a definite and clear definition of school belonging has not yet emerged.

Besides, though the researches have already expanded the participants from elementary and secondary school students to college students, from mainstreams to marginalized groups including minority ethnic, immigrant, refugee, transfer, remote-region and LGBT students, the researches still focus on a confined spectrum. Few researches delve into the school belonging of a variety of school staff, though there have been some surveys about the correlation between faculties' school belonging and other variables such as job satisfaction, self-efficacy and wellbeing(Skaalvik \& Skaalvik, 2011).

When referring to assessment of school belonging, it's worth noticing that most of the assessment take on the form of self-report scales, though there are some complementary methods. And most of the scalesderive from the PSSM scale. These scales either focus on general school belonging or specific aspects of school belonging such as relationships with peers and teachers, identification with school values as well as facilities and participation in extracurricular activities.

And the researchers should resort to more methods to assess school belonging. The researchers can focus more on experimental 
assessment, which can reveal the casual model of school belonging. And longitudinal studies are also indispensable in disclosing the development of school belonging. Furthermore, we should get down to cognitive mechanism of school belonging, which can bring vigor into this field. Though researches of school belonging have been conducted in many ethnic backgrounds, most of the researches have not yet brought out the characteristics of crossculture psychology. Investigators can delve into the effect of distinct factors on school belonging, such as the effect of generation status on school belonging.

As for the relationships between school belonging and other variables, the researchers primarily focus on academic performance, selfconception and problem behaviors. Though quantities of correlational researches have already reached consensus in these issues, experiments and longitudinal studies are still indispensable.

And there are controversial influential factors of school belonging. Though the effect of school climate and grades has not been challenged, the role of ethnicity and gender difference on school belonging has not been well received. There are still some researchers arguing that these factors do not have a significant impact on school belonging(Cueto et al., 2010). Therefore, this field urges for more longitudinal, experimental and cross-cultural investigations to find out the exact role of these factors.

\section{CONCLUSIONS}

The theories of school belonging includes stage-environment fit theory, self-determination theory and participation-identification theory. These theories have already been accomplished in early periods. Later investigators should concentrate mainly on throwing light upon ambiguity in these theories and supplementing some up-to-date contents and cross-cultural characteristics to enrich these theories.

\section{References}

[1]. Babakhani, N. (2014). Perception of Class and Sense of School Belonging and Self-regulated Learning: A Causal Model. Procedia-Social and Behavioral
Sciences, 116, 1477-1482.

[2]. Baumeister, R. F., \& Leary, M. R. (1995). The need to belong: desire for interpersonal attachments as a fundamental human motivation. Psychological bulletin, 117(3), 497.

[3]. Cemalcilar, Z. (2010). Schools as Socialisation Contexts: Understanding the Impact of School Climate Factors on Students' Sense of School Belonging. Applied Psychology: An International Review, 59(2), 243-272. doi: 10.1111/j.14640597.2009.00389.x

[4]. Coleman, S. H. C. (2013). THE RACIAL STRESS OF MEMBERSHIP: DEVELOPMENT OF THE FACULTY INVENTORY OF RACIALIZED EXPERIENCES IN SCHOOLS. Psychology in the Schools, 50(6), 548-566. doi: 10.1002/pits.21693

[5]. Covarrubias, R., \& Fryberg, S. A. (2014). The Impact of Self-Relevant Representations on School Belonging for Native American Students. Cultural Diversity and Ethnic Minority Psychology. doi: 10.1037/a0037819

[6]. Cueto, S., Guerrero, G., Sugimaru, C., \& Zevallos, A. M. (2010). Sense of belonging and transition to high schools in Peru. International Journal of Educational Development, 30(3), 277-287. doi: http://dx.doi.org/10.1016/j.ijedudev.2009.02.002

[7]. Drolet, M., Arcand, I., Ducharme, D., \& Leblanc, R. (2013). The sense of school belonging and implementation of a prevention program: Toward healthier interpersonal relationships among early adolescents. Child \& Adolescent Social Work Journal, 30(6), 535-551.

[8]. Eccles, J. S., Midgley, C., Wigfield, A., Buchanan, C. M., Reuman, D., Flanagan, C., \& Mac Iver, D. (1993). Development during adolescence: the impact of stage-environment fit on young adolescents' experiences in schools and in families. American psychologist, 48(2), 90.

[9]. Faircloth, B. S. (2009). Making the most of adolescence: Harnessing the search for identity to understand classroom belonging. Journal of Adolescent Research.

[10]. Faircloth, B. S., \& Hamm, J. V. (2005). Sense of belonging among high school students representing 4 ethnic groups. Journal of Youth and Adolescence, 34(4), 293-309.

[11]. Ferreira, M., Cardoso, A. P., \& Abrantes, J. L. (2011). Motivation and Relationship of the Student with the School as Factors Involved in the Perceived Learning. Procedia - Social and Behavioral Sciences, 29(0), 1707-1714. doi: http://dx.doi.org/10.1016/j.sbspro.2011.11.416

[12]. Flores, J. G., \& Clares-López, J. (2014). Bullying in 
Students Belonging to Immigrant Families in Primary Schools. Procedia - Social and Behavioral Sciences, 132(0), 621-625. doi: http://dx.doi.org/10.1016/i.sbspro.2014.04.363

[13]. Gagné, M. H., Shapka, J. D., \& Law, D. M. (2014). Moving Beyond Grades: The Social and Emotional Well-Being of Chinese Canadians at School. Asian American Journal of Psychology. doi: 10.1037/a0038243

[14]. Goldweber, A., Waasdorp, T. E., \& Bradshaw, C. P. (2013). Examining the link between forms of bullying behaviors and perceptions of safety and belonging among secondary school students. Journal of School Psychology, 51(4), 469-485. doi: http://dx.doi.org/10.1016/i.jsp.2013.04.004

[15]. Goodenow, C. (1993). The psychological sense of school membership among adolescents: Scale development and educational correlates. Psychology in the Schools, 30(1), 79-90.

[16]. Hagborg, W. J. (1994). An exploration of school membership among middle-and high-school students. Journal of Psychoeducational Assessment, 12(4), 312-323.

[17]. Hagborg, W. J. (1998). An investigation of a brief measure of school membership. Adolescence.

[18]. Lemberger, M. E. K. S. (2013). Individual Psychology and Factors Associated with the Development of Elementary and Secondary School Students. Journal of Individual Psychology, 69(1), 84-91.

[19]. Maurizi, L. K., Ceballo, R., Epstein - Ngo, Q., \& Cortina, K. S. (2013). Does neighborhood belonging matter? Examining school and neighborhood belonging as protective factors for Latino adolescents. American Journal of Orthopsychiatry, 83(2-3), 323-334. doi: 10.1111/ajop.12017

[20]. McMahon, S. D. P. A. L. K. C. B. V. J. J. (2008). School belonging among low-income urban youth with disabilities: Testing a theoretical model. Psychology in the Schools, 45(5), 387-401. doi: 10.1002/pits.20304

[21]. Neel, C. G.-O. F. A. (2013). A Longitudinal Study of School Belonging and Academic Motivation Across High School. Child Development, 84(2), 678-692. doi: 10.1111/j.1467-8624.2012.01862.x

[22]. O'Keeffe, P. (2013). A SENSE OF BELONGING: IMPROVING STUDENT RETENTION. College Student Journal, 47(4), 605-613.

[23]. Osborne, L. A., \& Reed, P. (2011). School factors associated with mainstream progress in secondary education for included pupils with Autism Spectrum Disorders. Research in Autism Spectrum Disorders, 5(3), 1253-1263. doi: http://dx.doi.org/10.1016/j.rasd.2011.01.016

[24]. Pittman, L. D. R. A. (2007). Academic and Psychological Functioning in Late Adolescence: The Importance of School Belonging. Journal of Experimental Education, 75(4), 270-290.

[25]. Rostosky, S. S., Owens, G. P., Zimmerman, R. S., \& Riggle, E. D. B. (2003). Associations among sexual attraction status, school belonging, and alcohol and marijuana use in rural high school students. Journal of Adolescence, 26(6), 741-751. doi: http://dx.doi.org/10.1016/j.adolescence.2003.09.00 $\underline{2}$

[26]. Sancho, M. T. (2012). Fostering a sense of belonging and community as children start a new school. Educational \& Child Psychology, 29(1), 64-74.

[27]. Skaalvik, E. M., \& Skaalvik, S. (2011). Teacher job satisfaction and motivation to leave the teaching profession: Relations with school context, feeling of belonging, and emotional exhaustion. Teaching and Teacher Education, 27(6), 1029-1038. doi: http://dx.doi.org/10.1016/j.tate.2011.04.001

[28]. Turner, I., Reynolds, K. J., Lee, E., Subasic, E., \& Bromhead, D. (2014). Well-being, school climate, and the social identity process: A latent growth model study of bullying perpetration and peer victimization. School Psychology Quarterly, 29(3), 320-335. doi: 10.1037/spq0000074

[29]. 10.1037/spq0000074.supp (Supplemental)

[30]. Wallace, T. L. F. V. (2012). Subdimensions of Adolescent Belonging in High School. Applied Developmental Science, 16(3), 122-139. doi: 10.1080/10888691.2012.695256

[31]. Walton, G. M., Cohen, G. L., Cwir, D., \& Spencer, S. J. (2012). Mere belonging: The power of social connections. J Pers Soc Psychol, 102(3), 513-532.

[32]. Wehlage, G. G. (1989). Dropping out: can schools be expected to prevent it: Dropouts from school: issues, dilemmas, and solutions. Albany, NY: State University of New York Press.

[33]. You, S., Ritchey, K., Furlong, M., Shochet, I., \& Boman, P. (2010). Examination of the latent structure of the Psychological Sense of School Membership Scale. Journal of Psychoeducational Assessment, 0734282910379968. 